\title{
MEGALOBLASTIC ANAEMIA COMPLICATING DIETARY TREATMENT OF PHENYLKETONURIA IN INFANCY
}

\author{
BY \\ N. J. W. ROYSTON* and T. E. PARRY \\ From the Department of Child Health, The Welsh National School of Medicine and the \\ Department of Clinical Pathology, Llandough Hospital, United Cardiff Hospitals
}

(RECEIVED FOR PUBLICATION FEBRUARY 14, 1962)

Nutritional deficiencies may complicate the treatment of phenylketonuria by 'synthetic' phenylalanine restricted diets. This danger is greatest in infancy when growth is rapid.

We report the occurrence of megaloblastic anaemia of infancy due to folic acid deficiency, during the dietary treatment of a baby with phenylketonuria.

\section{Case Report}

Simon B. was born at home on July 16,1960 , the third child of healthy unrelated parents. The pregnancy and delivery at full term were uneventful and his birth weight was $7 \frac{1}{2} \mathrm{lb}$. $(3.4 \mathrm{~kg}$.).

His eldest brother is mentally retarded and at the age of 7 years was found to have phenylketonuria; this was confirmed by paper chromatography of blood and urine. He has been on a low phenylalanine diet since that time with some improvement in his behaviour, but at 10 years old he has an I.Q. of 60 . The second child is a normal boy of 5 years. Chromatographic examination of the urine of the parents and the second boy showed no abnormality.

Simon appeared to be making normal progress on artificial milk feeds of half cream (Cow and Gate) and weighed $8 \mathrm{lb}$. $(3.6 \mathrm{~kg}$.) at 13 days old. Routine Phenistix testing of his urine at home by the Health Visitor at this time gave a strongly positive result, and he was admitted to hospital for investigation and dietary treatment.

He was a fair, blue-eyed baby of normal appearance. His urine Phenistix tests were consistently positive and urine and blood chromatograms gave good spots for phenylalanine. The serum phenylalanine level by a biochemical method was $37 \mathrm{mg}$. $/ 100 \mathrm{ml}$. (normal up to $3 \mathrm{mg}$.) The haemoglobin was $120 \%$ and the white blood cells numbered $15,800 / \mathrm{c} . \mathrm{mm}$. with normal differential count.

His normal milk feeds were replaced by a phenylalanine-restricted diet from the age of 2 weeks. For the initial depletion period 'minafen' was used in a 1 in 8 dilution, $25 \mathrm{oz}$. daily (20-25 mg. phenylalanine and 770 calories per day) with an 'abidec' vitamin supplement of

* Present address: The Hospital for Sick Children, Great Ormond Street, London W.C.1.
10 drops daily. The urine Phenistix tests became negative, and he was discharged at 1 month old weighing $7 \mathrm{lb} .13 \mathrm{oz} .(3 \cdot 5 \mathrm{~kg}$.) to continue his diet at home.

He made disappointing progress, taking his feeds reluctantly with frequent vomiting and failure to gain weight. At 6 weeks of age his urine and blood chromatograms showed less marked phenylalanine spots, and a week later his serum phenylalanine level was $1 \mathrm{mg}$./ $100 \mathrm{ml}$. by the same chemical technique as previously. In spite of his poor physical progress he appeared to be a normally alert and responsive infant with a D.Q. of 120 at 7 weeks. Over the next three weeks his weight remained static and he became anaemic, his haemoglobin level falling to $58 \%$ and peripheral blood film showing moderate hypochromia with some anisocytosis.

Double cream was added to his diet, $2 \cdot 5 \mathrm{oz}$. per day, to give an additional $70 \mathrm{mg}$. of phenylalanine per day, raising his intake to about $25 \mathrm{mg}$. $/ \mathrm{kg}$. body weight $/$ day. 'Sytron' (sodium ironedetate) $\frac{1}{2}$ dr. t.d.s. was prescribed for his anaemia.

The feeding difficulties persisted with troublesome vomiting, and at the age of 3 months he was readmitted to hospital (second admission) weighing $8 \mathrm{lb} .11 \mathrm{oz}$. $(3.9 \mathrm{~kg}$.), only $1 \mathrm{lb}$. $(0.45 \mathrm{~kg}$.) over his birth weight and only $11 \mathrm{oz}$. $(0 \cdot 3 \mathrm{~kg}$.) heavier than when he started treatment. He was now a pale, puny and fretful infant with signs of respiratory tract infection and a temperature of $102^{\circ} \mathrm{F}$. $\left(38 \cdot 9^{\circ} \mathrm{C}\right.$.) per rectum. There was no rash or evidence of convulsions. The Phenistix tests remained negative. His haemoglobin was $63 \%$, and the peripheral blood film showed marked anisocytosis and hypochromia. White blood cells were $8,600 / \mathrm{c} . \mathrm{mm}$.; polymorphs $33 \%$; lymphocytes $54 \%$; monocytes $12 \%$; eosinophils $1 \%$. Chest radiograph was normal. Plasma electrolytes normal.

There was no improvement when he was fed by tube. and artificial milk feeds of half cream Cow and Gate were given for a week in an attempt to achieve a gain in weight. The vomiting stopped, but there was no increase in his weight. The urine Phenistix tests became positive and the plasma phenylalanine level varied between $15.3 \mathrm{mg} . / 100 \mathrm{ml}$. (microbiological assay) and $20 \mathrm{mg}$./ $100 \mathrm{ml}$. (quantitative paper chromatography).

A low phenylalanine diet was resumed using 'cymogran' (Allen and Hanburys) 45 g. daily with 14 
teaspoons of sugar, $2 \mathrm{oz}$. of double cream and $0.5 \mathrm{oz}$. of fresh cows' milk to $26 \cdot 5 \mathrm{oz}$. water $(80 \mathrm{mg}$. phenylalanine and 600 calories per day; equivalent to $20 \mathrm{mg}$. $/ \mathrm{kg}$. body weight/day of phenylalanine). This was better tolerated with infrequent vomiting, but he gained only 4 or $5 \mathrm{oz}$. over the next three weeks in hospital. The serum phenylalanine level fell to $1.8 \mathrm{mg} . / 100 \mathrm{ml}$. (microbiological assay) and the haemoglobin to $40 \%$. A week later the haemoglobin was $48 \%$ and the mean corpuscular haemoglobin concentration (M.C.H.C.) was $21 \%$; a whole blood transfusion of $150 \mathrm{ml}$. was given to correct his anaemia.

The same diet was continued after he returned home at 17 weeks of age, but he still weighed $9 \mathrm{lb} .(4.08 \mathrm{~kg}$.) three weeks later and another $0.5 \mathrm{oz}$. of fresh cows' milk daily was added to his diet. His haemoglobin dropped from $62 \%$ to $38 \%$ in the course of the next month, and the peripheral blood film again showed hypochromia and anisocytosis, although the oral iron supplement had been maintained.

He was readmitted at 5 months of age (third admission) for a second blood transfusion which raised his haemoglobin to $111 \%$. Three weeks later the haemoglobin had dropped again to $88 \%$, erythrocytes $4,410,000 /$ c.mm.; colour index 1.0; packed cell volume (P.C.V.) $40 \%$; mean corpuscular volume (M.C.V.) 91 c. $\mu$; M.C.H.C. $32 \cdot 5 \%$.

On his return home after this transfusion he continued to refuse his feeds, to vomit and to fail to thrive, and he came back into hospital (fourth admission) when he was 6 months old weighing $8 \mathrm{lb} .7 \mathrm{oz}$. $(3 \cdot 8 \mathrm{~kg}$.). For a week full-cream Cow and Gate milk feeds were given by intragastric tube with an impressive weight gain of $12 \mathrm{oz}$. $(0.34 \mathrm{~kg}$.), in spite of occasional large vomits. The Phenistix tests became strongly positive again and a more restricted phenylalanine diet was reintroduced, given by intragastric tube, of 'cymogran' $100 \mathrm{~g}$., double cream 2 oz., full cream artificial milk $1 \mathrm{oz}$., sugar 15 teaspoons and $36 \mathrm{oz}$. of water per day $(120 \mathrm{mg}$. phenylalanine and 850 calories per day; equivalent to $30 \mathrm{mg}$./ kg./day phenylalanine). The vomiting became more frequent, and there was a precipitous drop in weight after five days of this diet.

At this readmission he was pale, lethargic and hypotonic. He was unable to sit up without support. There was no rash, and again no history was obtained of convulsions. His haemoglobin was $66 \%$, falling a week later to $50 \%$; erythrocytes $2,262,000 /$ c.mm.; colour index $1 \cdot 1$; P.C.V. $21 \%$; M.C.V. 90 c. $\mu$; M.C.H.C. $36 \%$; reticulocytes $0 \cdot 2 \%$; platelets $59,000 /$ c.mm.; white blood cells $6,450 /$ c.mm.; erythrocyte sedimentation rate (Wintrobe) $72 \mathrm{~mm}$./hour (corrected for anaemia-21). The film showed moderate anisocytosis.

An iliac crest biopsy at this time showed a moderately cellular marrow with entirely megaloblastic erythropoiesis (Fig. 1). The appearances were indistinguishable from the marrow in adult cases of Addisonian anaemia in relapse and were most unusual in an infant of 6 months. This megaloblastic anaemia was presumed to be of nutritional origin, resulting from his restricted diet, and probably due to folic acid deficiency. In addition, myelopoiesis was grossly abnormal (see below).

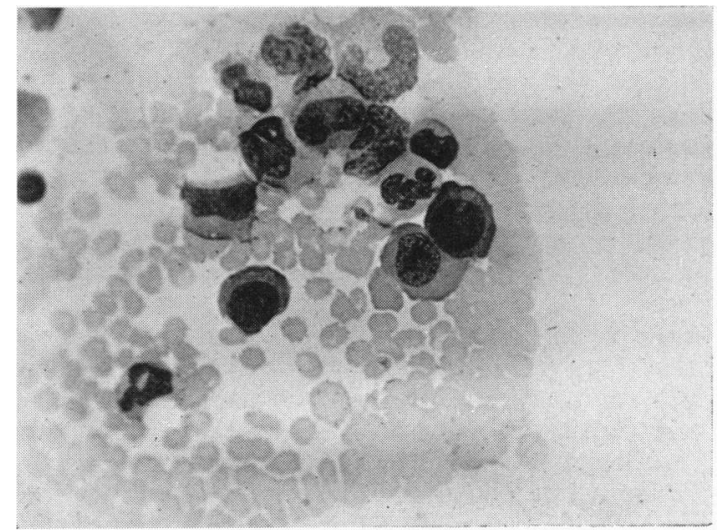

a.

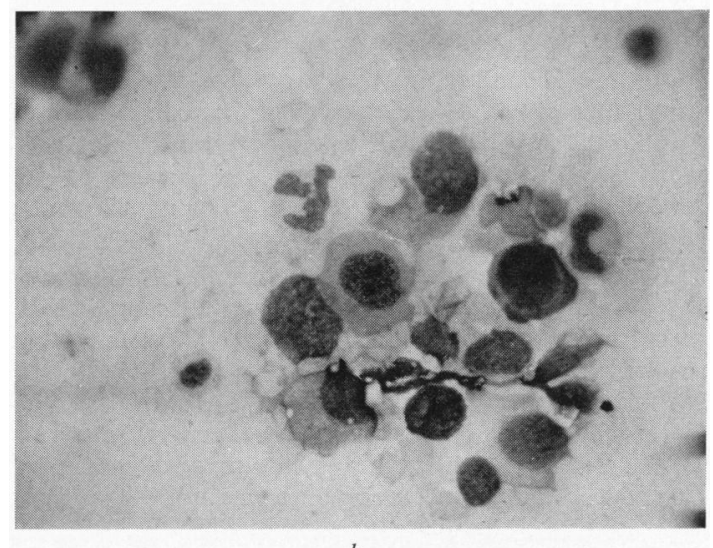

$b$.

Fig. 1.-Marrow at 28 weeks, showing megaloblastic erythropoiesis a. Partly haemoglobinized Ehrlich megaloblast with an adjacent pro-erythroblast with deeply basophilic cytoplasm. A giant metamyelocyte is seen at the top of the figure. $(\times 344$.

b. Haemoglobinized Ehrlich megaloblast with a pro-erythroblast, the latter having a deeply basophilic cytoplasm with a perinuclear pale zone. $(\times 344$.)

An average of two separate assays showed the total serum $B_{12}$ to be $328 \mu \mu \mathrm{g} . / \mathrm{ml}$. [Normal range $100-720$ $\mu \mu \mathrm{g} . / \mathrm{ml}$. (Mollin and Ross, 1952).] There was no significant reticulocyte response to a single intramuscular dose of $50 \mu \mathrm{g}$. of vitamin $\mathrm{B}_{12}$, and before the effect of folic acid could be tried Simon suddenly deteriorated with extreme respiratory distress, tachycardia and fever of $102^{\circ}$ F. $\left(38.9^{\circ}\right.$ C. $)$. There were signs of bronchopneumonia, but antibiotic therapy and nursing in an oxygen tent failed to bring about any improvement, and he collapsed and died two days later on February 5, 1961.

Autopsy. The body was that of an extremely pale, wasted and slightly oedematous male infant weighing $4,320 \mathrm{~g}$. About $50 \mathrm{ml}$. of clear straw-coloured fluid was present in the right pleural cavity and about $30 \mathrm{ml}$. in the left. A small amount of white frothy material was present in the trachea and main bronchi. Both lungs 
were oedematous and showed basal hypostatic congestion with petechiae under the basal and mediastinal pleurae. The right lung weighed $72 \mathrm{~g}$. and the left $58 \mathrm{~g}$. The heart weighed $28 \mathrm{~g}$. The myocardium was extremely pale. All the chambers, particularly the left ventricle were dilated. Apart from dilatation of the stomach the gastro-intestinal tract was normal. Ascites was not present. The mesenteric glands were enlarged and pale. The liver (210 g.) was pale but otherwise normal. The spleen (17 g.) was slightly enlarged and red in colour with normal markings. The kidneys (right $23 \mathrm{~g}$.; left $26 \mathrm{~g}$.) showed extreme cortical pallor which contrasted strongly with the congested medulla. The brain $(210 \mathrm{~g}$.) showed no abnormality. There was a moderate degree of kyphoscoliosis. Pathogenic organisms were not grown from swabs taken from the main bronchi. Lung tissue was cultured for viruses with negative results.

\section{Microscopical Appearances}

LUNGS. The alveolar walls were engorged and the alveoli themselves oedematous with occasional foci of alveolar haemorrhages. The smaller bronchioles contained a purulent exudate which was present in the immediately surrounding alveoli. The interlobular septae were widened and oedematous.

LIVER. The architecture was normal. A moderate degree of fatty change, centrilobular in distribution, was present. Haemosiderin deposition was evident in the parenchymal cells in the outer zone of each liver lobule. Extramedullary erythropoiesis was not present. Haemosiderin-laden phagocytes were likewise seen in the spleen, marrow, lymph nodes and in the capsule of the pancreas. A reliable opinion on the type of erythropoiesis could not be given on the marrow on account of post-mortem change.

KIDNEYS. Small foci of metastatic calcification were evident in the medulla mainly within the lumina of collecting tubules. These were present in both kidneys which were otherwise normal.

BRAIN. There was evidence of nerve cell degeneration with dilatation of the Virchow-Robin spaces. These findings are not, however, regarded as specific. There was a paucity of nerve cells, patchy in distribution, in the outer pyramidal layer (layer 111) of the cerebral cortex. The myocardium, adrenals and pancreas did not show any histological abnormality. The immediate cause of death was suppurative bronchiolitis and left ventricular failure.

\section{Dietary Investigations}

Through the courtesy of Dr. J. L. Withey it was possible to assay retrospectively the folic acid content of 'minafen' and 'cymogran' as well as that of National dried milk. The test organism employed was Streptococcus faecalis. The (duplicate) results are shown in the Table.

The relation of the anaemia to the administration of these preparations is shown in Fig. 2. Anaemia,

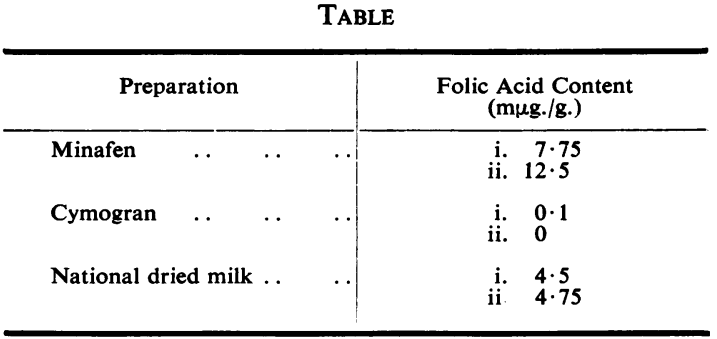

though present, had not been a serious problem up to 12 weeks. Moreover, this was an iron deficiency anaemia as shown by hypochromia in the peripheral blood film and a slight response to iron therapy. From 12 weeks onwards, however, the anaemia became much more pronounced, the haemoglobin falling $20 \%$ in less than a fortnight and necessitating blood transfusions in the fifteenth and 23rd weeks. There was a marked iron deficiency at 15 weeks, the M.C.H.C. being $21 \%$. The sharp fall in haemoglobin in the thirteenth week coincided with a respiratory infection and the period of extreme feeding difficulties already described. Minafen and half cream Cow and Gate were in turn administered by intragastric drip during the thirteenth and fourteenth weeks. Cymogran was substituted for 'minafen' during the fifteenth week and continued up until the infant's death. The patient was on oral iron from 10 weeks onwards, and the iron deficiency had been corrected by the time the marrow biopsy was done, the M.C.H.C. then being $36 \%$. The normocytic normochromic anaemia associated with megaloblastic erythropoiesis developed after a period of 13 weeks on a diet in which the main source of protein was a low phenylalanine preparation in which the presence of folic acid could not be detected by the method employed. It is, therefore, submitted that the megaloblastic anaemia in this case was due to nutritional folic acid deficiency.

\section{Discussion}

Nutritional megaloblastic anaemia of infancy is extremely rare in this country. Single cases have been described (Hutchison and MacArthur, 1949; Rickards, 1952) in infant girls of 17 and 8 months respectively. The hyperchromic anaemia in a girl aged 5 weeks which responded dramatically to a single dose of liver extract (Cole, 1941) probably belongs to the same group, although the marrow was not examined in this case. The disease has, however, been more prevalent in other countries. Reports from the United States (Zuelzer and Ogden, 1946; Zuelzer and Rutzky, 1953; Luhby, 


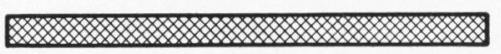

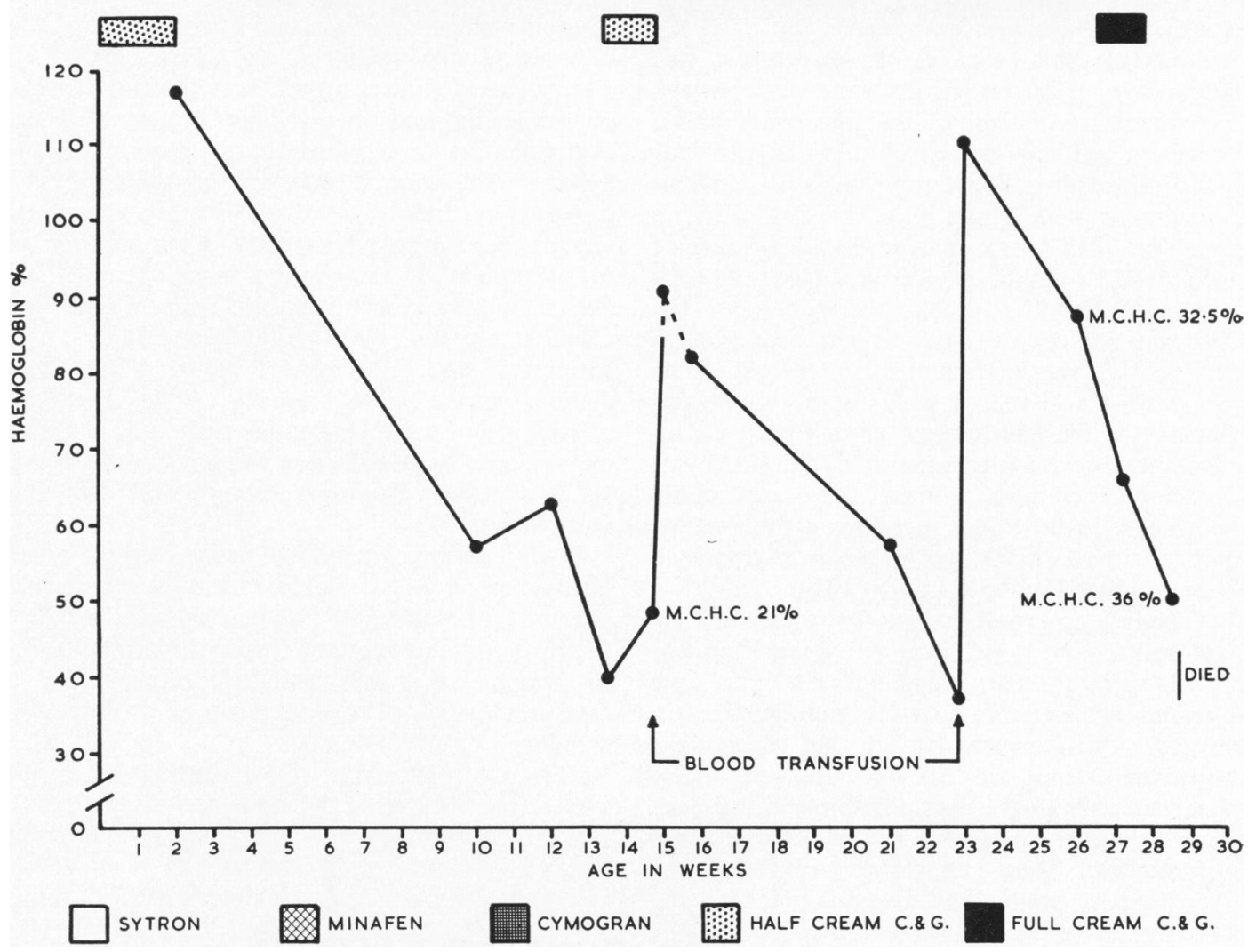

FIG. 2.-Chart showing the relation between the anaemia and the diet (for details see text).

1959) show a remarkable rise in the incidence of the disease between 1946 and 1953 and its virtual disappearance since. Amato (1946) reported a large series from Italy soon after Zuelzer and Ogden's first report from the United States.

Megaloblastic anaemia of infancy accounted for $5.4 \%$ of all paediatric admissions in one year in Durban (Walt, Holman and Hendrickse, 1956) and for $6.3 \%$ of similar admissions to the University College Hospital, Jamaica, in 1957 (MacIver and Back, 1960).

Although folic acid deficiency is regarded as the aetiology, prolonged infection is an important factor in conditioning the deficiency at this age. Ascorbic acid deficiency appears to be a further predisposing factor, probably by virtue of the enhancement, by vitamin $\mathrm{C}$, of the conversion of folic acid into its metabolically active form citrovorum factor
(Zuelzer and Rutzky, 1953). Protein deficiency per se resulting from the restricted diet is considered an unlikely cause of the anaemia in our case because of the rarity of this type of anaemia in true protein malnutrition (Woodruff, 1955; Adams, 1954; Kho-Lien-Keng, Poesponegoro and PoeySeng-Hin, 1957).

The occurrence of megaloblastic anaemia as a complication of a low phenylalanine diet in the treatment of phenylketonuria has not previously been reported in detail. Hudson (1961) in a recent letter to the British Medical Journal mentions a case which developed 'severe gastroenteritis with megaloblastic anaemia when some vitamins were inadvertently omitted'. Haematological details were not given. In a one-year controlled study of the effect of a low phenylalanine diet Hsia, Knox, Quin and Paine (1958) did not consider anaemia as a serious 
problem in adult phenylketonurics, but the haemoglobin level of eight of the 13 children in their series fell to below $10 \mathrm{~g} . / 100 \mathrm{ml}$. during the second half of the period of study. The marrows of these cases were not, however, examined.

The anaemia in our case was normocytic and normochromic. The absence of macrocytosis was at first surprising in view of the marrow findings. The anaemia has been described as usually normocytic and normochromic (MacIver and Back, 1960) or normocytic with slight hypochromia (Luhby, 1959). The M.C.V. was below 100 c. $\mu$ in nine of the series of 25 cases of Zuelzer and Ogden (1946), the lowest being $72 \mathrm{c} . \mu$. In the remainder the M.C.V. was 100 c. $\mu$ or over. It was over 120 c. $\mu$ in four cases, the highest being 156 c. $\mu$. The frequent absence of macrocytosis is important and may delay the marrow biopsy, as in fact it did in the present case. Leucopenia and thrombocytopenia accompanied the anaemia. This pancytopenia in the absence of infection, is characteristic and has been noted in nearly all the larger series reported (Zuelzer and Rutzky, 1953; Luhby, 1959).

The changes in myelopoiesis first described by Zuelzer and Ogden (1946) were pronounced in our case. Many of the early myeloid cells were large with abundant immature sparsely granulated cytoplasm resembling promyelocytes, yet the nuclei showed indentation and early lobulation. These changes were seen in their extreme form in the giant metamyelocyte. Hypersegmented polymorphs were also prominent. These changes are well recognized in Addisonian pernicious anaemia. It is our impression, however, that they are more marked in folic acid deficiency than in vitamin $\mathbf{B}_{12}$ deficiency states, and it is significant that MacIver and Back (1960) found unmistakable changes in the white cells in the marrow in the absence of typical megaloblasts in cases which responded to folic acid.

Dangers of Dietary Restriction. In the past few years there has been an increasing awareness of the special problem of dietary treatment of phenylketonuria during infancy. The need for early treatment to avoid mental retardation is clearly established, and there are several reports of successful dietary management begun in the first few weeks of life (Brimblecombe, Stoneman and Maliphant, 1959; Horner and Streamer, 1959). In some cases, however, deficiency disease has complicated the use of these diets during this stage of rapid normal growth, and it is not yet known whether all the essentials for normal growth are provided in adequate amounts by the low phenylalanine diets available at present. The diet must not only be comprehensive to avoid nutritional deficiency, but must also be palatable, and this proved to be a considerable problem in the case we report, because refusal of feeds and vomiting aggravated any inherent deficiency in the diet offered.

Assessment of progress, we believe, must be to a large extent clinical rather than by rigid insistence on achieving and maintaining a normal plasma phenylalanine level which may bring in its train dietary deficiency impairing growth. A more generous phenylalanine intake during infancy has already been recommended by other authors even to the extent of raising the serum phenylalanine above the upper limit of normal (Snyderman, Pratt, Cheung, Norton, Hold, Hansen and Panos, 1955; Moncrieff and Wilkinson, 1961). The phenylalanine intake of $15 \mathrm{mg} . / \mathrm{kg}$. body weight/day originally suggested by Blainey and Gulliford (1956) may have to be increased in some infants to $40 \mathrm{mg}$./ $\mathrm{kg}$./day or more (Brimblecombe, Blainey, Stoneman and Wood, 1961).

Until a simpler method of estimating the plasma phenylalanine is available, accurate biochemical control by regular and frequent estimations during the early stages of dietary treatment will be difficult to arrange in those paediatric units where the management of phenylketonuria is an occasional problem.

The more generous phenylalanine intake that may be needed during the rapid growth phase in the first six months of life might be more easily regulated by frequent urine testing for phenylketone, as keeping the urine negative will probably prevent the serum phenylalanine level from rising above $12 \mathrm{mg} . / 100 \mathrm{ml}$. (Armstrong and Low, 1957).

\section{Summary}

A detailed case report is given of megaloblastic anaemia of infancy occurring during the dietary treatment of phenylketonuria. The anaemia is considered to be nutritional in origin, due to folic acid deficiency, and the importance of an adequate daily folic acid supplement to low phenylalanine diets is argued.

The literature of megaloblastic anaemia in infancy is reviewed and the frequent absence of macrocytosis in the peripheral blood in association with megaloblastic erythropoiesis in this age group is noted. We suggest that marrow biopsy should be performed more frequently in the investigation of anaemia in infancy.

The problems encountered in dietary management and biochemical control of infants with phenylketonuria are discussed. Our experience 
supports the view that a more generous diet may be needed to avoid other unrecognized nutritional deficiency in these infants.

Frequent clinical assessment is the most important means of checking progress and temporary relaxation of the diet may be necessary if there is failure to thrive.

We would like to thank Professor A. G. Watkins for permission to publish the case and for his constant help and encouragement; Dr. N. K. Gibbs for referring the patient and for her D.Q. assessment; Dr. J. D. Blainey and Mr. R. A. Saunders for plasma phenylalanine estimations; Professor J. Gough and Dr. E. E. Payne for their opinion on the sections of the brain; Dr. J. L. Withey for the folic acid and $B_{12}$ estimations; Dr. H. N. H. Genese (Mead Johnson, Ltd.), Dr. G. R. Boyes (Allen and Hanburys, Ltd.), and Mr. F. P. Diggins (Paines and Byrne, Ltd.) for references on the subject and information about the products of their companies; Miss Powell, Dietician, Cardiff Royal Infirmary, for assistance with the low phenylalanine diets and Miss Davey, Health Visitor, Public Health Department, Cardiff, for visiting the family and supervising the diet at home.

\section{REFERENCES}

Adams, E. B. (1954). Anaemia in kwashiorkor. Brit. med. J., 1, 537 .

Amato, M. (1946). Rilievi anamnestico-clinici, ematologici e biochemici e considerazioni pathogenetiche su 25 casi di anemie ipercromiche megaloblastiche osservate in bambini della prima infanzia. Pediatria (Napoli), 54, 71 .

Armstrong, M. D. and Low, N. L. (1957). Phenylketonuria VIII. Relation between age, serum phenylalanine level, and phenylpyruvic acid excretion. Proc. Soc. exp. Biol. (N.Y.), 94, 142.
Blainey, J. D. and Gulliford, R. (1956). Phenylalanine-restricted diets in the treatment of phenylketonuria. Arch. Dis. Childh., 31, 452.

Brimblecombe, F. S. W., Blainey, J. D., Stoneman, M. E. R. and Wood, B. S. B. (1961). Dietary and biochemical control of phenylketonuria. Brit. med. J., 2, 793.

, Stoneman, M. E. R. and Maliphant, R. (1959). Dietary treatment of an infant with phenylketonuria. Lancet, 1, 609 .

Cole, L. (1941). Hyperchromic anaemia in an infant; response to liver extract. ibid., 2, 759.

Horner, F. A. and Streamer, C. W. (1959). Phenylketonuria treated from earliest infancy; report of three cases. A.M.A.Amer.J. Dis. Child., 97, 345.

Hsia, D. Y., Knox, W. E., Quin, K. V. and Paine, R. S. (1958). A one-year, controlled study of the effect of low-phenylalanine diet on phenylketonuria. Pediatrics, 21, 178.

Hudson, F. P. (1961). Phenylketonuria. Letter to the Editor. Brit. med. J., $1,1105$.

Hutchison, J. H. and MacArthur, P. (1949). Megaloblastic anaemia in an infant Lancet, 1, 916.

Kho-Lien-Keng, Poesponegoro, S. D. and Poey-Seng-Hin (1957). The bone marrow picture in kwashiorkor in Djakarta. Docum. med. geogr. trop. (Amst.), 9, 69.

Luhby, A. L. (1959). Megaloblastic anemia in infancy. III. Clinical considerations and analysis. J. Pediat., 54, 617 .

MacIver, J. E. and Back. E. H. (1960). Megaloblastic anaemia of infancy in Jamaica. Arch. Dis. Childh., 35, 134.

Mollin, D. L. and Ross, G. I. M. (1952). The vitamin B12 concentrations of serum and urine of normals and of patients with megaloblastic anaemias and other diseases. J. clin. Path., 5, 129.

Moncrieff, A. and Wilkinson, R. H. (1961). Further experiences in the treatment of phenylketonuria. Brit. med. J., 1. 763.

Rickards, A. G. (1952). Megaloblastic anaemia of infancy. ibid., 1,1226 .

Snyderman, S. E., Pratt, E. L., Cheung, M. W., Norton, P., Hold, L. E., Jr., Hansen, A. E. and Panos, T. C. (1955). The phenylL. E., Jr., Hansen, A. E. and Panos, T. C. (1955). The phent
alanine requirement of the normal infant. J. Nutr., 56, 253 .

Walt, F., Holman, S. and Hendrickse, R. G. (1956). Megaloblastic anaemia of infancy in kwashiorkor and other diseases. Brit. med. J., 1, 1199.

Woodruff, A. W. (1955). The natural history of anaemia associated with protein malnutrition. ibid., 1, 1297.

Zuelzer. W. W. and Ogden, F. N. (1946). Megaloblastic anemia in infancy; common syndrome responding specifically to folic acid therapy. Amer. J. Dis. Child., 71, 211 .

_- and Rutzky, J. (1953). Megaloblastic anaemia of infancy. Advanc. Pediat., 6, 243. 